\title{
Efeito do Óleo de Mamona em Composições de Borracha Natural Contendo Sílica
}

\author{
Helson M. da Costa, Valéria D. Ramos \\ Departamento de Materiais, UERJ
}

\author{
Thomas A. S. Abrantes, Daniele F. de Castro, Leila L. Y. Visconte, Regina C. R. Nunes \\ IMA, UFRJ
}

\author{
Cristina R. G. Furtado \\ Departamento de Processos Químicos, IQ, UERJ
}

\begin{abstract}
Resumo: O potencial do óleo de mamona como um ativador para a vulcanização de composições de borracha natural (NR) contendo sílica foi investigado. Utilizando-se um planejamento de experimentos adequado, manteve-se a concentração de sílica e outros aditivos constantes enquanto as quantidades de ácido esteárico, óleo de mamona e poli(etileno-glicol) foram variadas. A cura foi conduzida em um reômetro de disco oscilatório TI-100 e a variável de controle escolhida foi a resistência à tração. Os resultados demonstraram que o óleo de mamona sozinho não exerce influência considerável sobre o desempenho mecânico da borracha natural em presença de sílica.
\end{abstract}

Palavras-chaves: Borracha natural, óleo de mamona, sílica, planejamento de experimentos.

\section{Effects from the Castor Oil on Silica-Filled Natural Rubber Compounds}

\begin{abstract}
The possible use of castor oil fatty acid as an activator for the vulcanization reaction in silica-filled natural rubber (NR) compounds was investigated. The design and analysis of the experiments were carried out by keeping constant the concentration of silica and the other ingredients while the amounts of stearic acid, castor oil and poly(ethylene glycol) were varied. Cure was carried out on a TI-100 oscillating disk rheometer, and the tensile strength was chosen as the control variable. The results show that the addition of castor oil does not significantly change the mechanical performance of silica-filled natural rubber compounds.
\end{abstract}

Keywords: Natural rubber, castor oil, silica, design of experiments.

\section{Introdução}

A semente de mamona é constituída de $75 \%$ de amêndoa e $25 \%$ casca, em termos médios. Sua composição química muda de acordo com a variedade e região de cultivo. O teor de óleo nas sementes situa-se, entre $35 \%$ e $55 \%$. O padrão comercial adotado é de $44 \%$. Praticamente toda a produção da mamona é industrializada, obtendo-se como produto principal o óleo e como subproduto a torta de mamona, que tem grande capacidade de restauração de terras esgotadas. A extração do óleo é feita a partir da semente completa (sem descascar) ou da baga (semente descascada por meio de máquinas apropriadas). O método utilizado para extrair o óleo pode ser prensagem, a frio ou a quente, ou extração por solvente.

O óleo é o mais importante constituinte da semente de mamona, sendo o ácido ricinoléico o seu maior componente, $\mathrm{CH}_{3}\left(\mathrm{CH}_{2}\right)_{5} \mathrm{CH}(\mathrm{OH}) \mathrm{CH}_{2} \mathrm{CH}=\mathrm{CH}\left(\mathrm{CH}_{2}\right)_{7} \mathrm{COOH}$. O grupo hidroxila confere ao óleo da mamona a propriedade de álcool. Além disso, é um óleo bastante estável em variadas condições de pressão e temperatura.
As aplicações do óleo são inúmeras. Ele pode ser usado na fabricação de tintas e isolantes, serve como lubrificante na aeronáutica, como base na manufatura de cosméticos e de muitos tipos de drogas farmacêuticas. O óleo de mamona também é empregado em vários processos industriais, como a fabricação de corantes, anilinas, desinfetantes, germicidas, óleos lubrificantes de baixa temperatura, colas e aderentes, base para fungicidas e inseticidas, tintas de impressão e vernizes, além de nylon e matéria plástica, em que tem bastante importância.

Os efeitos de ácidos graxos derivados de óleos vegetais sobre a vulcanização, propriedades dinâmico-mecânicas, reversão e resistência à fadiga têm sido estudados em composições de borracha natural (SMR L) e de borracha natural epoxidada (ENR 25 e ENR 50) por Ismail et al..$^{[1-5]}$. Contudo, tais investigações têm sido restritas ao óleo de palma e a composições sem carga ou contendo negro de fumo ou carbonato de cálcio; por outro lado, sílica ainda não foi alvo de atenção.

Desta forma, o objetivo deste trabalho é verificar a influência do óleo de mamona sobre a vulcanização de com-

Autor para correspondência: Leila L. Y. Visconte, UFRJ/IMA, Centro de Tecnologia, Bloco J, Caixa Postal 68525, CEP: 21945-970, Rio de Janeiro, RJ. E-mail: lyv@ima.ufrj.br 
posições de borracha natural (NR) contendo sílica. A intenção é determinar se o óleo de mamona pode atuar como um ativador e/ou como um aditivo corretor do efeito adverso que a sílica provoca sobre a velocidade de cura. Utilizando-se o planejamento de experimentos $2^{3}$ (três fatores, $\mathrm{X}_{1}, \mathrm{X}_{2}$ e $\mathrm{X}_{3}$, em dois níveis, com triplicatas) manteve-se a concentração de sílica e de outros ingredientes constantes enquanto os teores de poli(etileno-glicol) $\left(\mathrm{X}_{1}\right)$, ácido esteárico $\left(\mathrm{X}_{2}\right)$ e óleo de mamona $\left(\mathrm{X}_{3}\right)$ foram variados. A variável de controle escolhida foi a resistência à tração.

\section{Experimental}

\section{Materiais e métodos}

Todos os materiais foram usados como recebidos. A borracha natural foi fornecida pela Celsoft Industrial e Comercial Ltda, enquanto a sílica (Zeosil-175) foi doada pela Rhodia do Brasil Ltda. O antioxidante (Banox H) e o acelerador (Banac CBS) foram obtidos junto a Uniroyal Química S. A. Os outros ingredientes - enxofre, óxido de zinco, ácido esteárico e poli(etileno-glicol) - foram reagentes de grau analítico. O óleo de mamona, fornecido pela EMBRAPA (Empresa Brasileira de Pesquisa Agropecuária), apresenta as especificações listadas na Tabela 1.

A formulação empregada para a cura e a posterior avaliação de propriedade mecânica encontra-se na Tabela 2. As características da sílica usada estão na Tabela 3. A área superficial foi calculada através do método Brunauer-Emmet-

Tabela 1. Composição do óleo de mamona e especificações

\begin{tabular}{cc}
\hline Ácidos graxos & $\%$ \\
\hline Ricinoléico & 80,5 \\
Linoléico & 4,2 \\
Oléico & 3,0 \\
Palmítico & 1,0 \\
Esteárico & 1,0 \\
9,10-Di-hidróxi-esteárico & 0,7 \\
Eicosanóico & 0,3 \\
Linolênico & 0,3 \\
\hline Propriedades & Especificações \\
\hline Claridade & Limpo \\
Valor de hidroxila & $160-168$ \\
Perda ao fogo, \% máx. & 0,3 \\
Valor de saponificação & $176-184$ \\
Índice de refração $\left(25{ }^{\circ} \mathrm{C}\right)$ & $0,957-0,961$ \\
\hline$\left.{ }^{\circ} \mathrm{C}\right)$ & $1,440-1,4780$ \\
\hline
\end{tabular}

Tabela 2. Formulação usada para as composições de NR

\begin{tabular}{lc}
\hline \multicolumn{1}{c}{ Material } & Phr \\
\hline Borracha natural & 100 \\
Óxido de zinco & 3,5 \\
Sílica & 25 \\
Ácido esteárico & Variável \\
Banac CBS & 0,8 \\
Óleo de mamona & Variável \\
Banox H & 2,0 \\
Poli(etileno-glico) (PEG) & Variável \\
Enxofre & 2,5 \\
\hline
\end{tabular}

${ }^{a} \mathrm{~N}$-ciclohexil-2-benzotiazol-sulfenamida

${ }^{\mathrm{b}}$ Antioxidante: 1,2-dihidro-2,2,4-trimetil-quinolina polimerizada

Tabela 3. Características da sílica usada

\begin{tabular}{lc}
\hline \multicolumn{1}{c}{ Propriedade } & Valor \\
\hline Tamanho médio de partícula $(\mu \mathrm{m})$ & 0,018 \\
Área específica $\left(\mathrm{m}^{2} / \mathrm{g}\right)$ & 185 \\
Densidade $\left(\mathrm{g} / \mathrm{cm}^{3}\right)$ & 2,0 \\
$\mathrm{pH}$ & 6,5 \\
\hline
\end{tabular}

Teller (BET) utilizando-se o equipamento ASAP 2010 Accelerated Surface Area and Porosimetry System. A densidade da carga foi calculada através de um picnômetro de vidro e o $\mathrm{pH}$ determinado de acordo com o método ASTM D 1512 .

\section{Preparação das misturas, reometria e preparação das amostras para ensaio}

A mistura foi conduzida em um misturador de cilindros aquecido a $70{ }^{\circ} \mathrm{C}$ com razão de velocidade entre os cilindros de 1:1,25 seguindo-se a norma ASTM D 3182. Após a mistura, a composição foi retirada do equipamento e pesada, se o valor encontrado fosse diferente do valor teórico mais do que $0,5 \%$, a composição era descartada.

A composição foi condicionada em $25 \pm 2{ }^{\circ} \mathrm{C}$ por 24 horas em local apropriado e, então, o tempo ótimo de cura foi determinado com auxílio de um reômetro de disco oscilatório, modelo TI-100, usando-se arco $3^{\circ}$ e temperatura de $150{ }^{\circ} \mathrm{C}$. Para o ensaio de resistência à tração, os corpos de prova foram retirados do material vulcanizado preparado por moldagem por compressão em uma prensa quente operando a $150{ }^{\circ} \mathrm{C} \mathrm{e}$ com 3,0 MPa.

O ensaio de resistência à tração foi realizado em uma máquina de ensaios universal, modelo Instron 1101, utilizandose corpos de prova, modelo dumbell tipo $\mathrm{C}$, de acordo com a norma ASTM D 412. 
Tabela 4. Níveis das variáveis $\mathrm{X}_{1}, \mathrm{X}_{2}$ e $\mathrm{X}_{3}$ (em phr)

\begin{tabular}{lcc}
\hline \multicolumn{1}{c}{ Variável } & \multicolumn{2}{c}{ Nível } \\
\hline & Baixo (-) & Alto $(+)$ \\
$\mathrm{X}_{1}$ (PEG) & 0 & 2,0 \\
$\mathrm{X}_{2}$ (Ácido esteárico) & 0 & 2,5 \\
$\mathrm{X}_{3}$ (Óleo de mamona) & 0 & 5,0 \\
\hline
\end{tabular}

Tabela 5. Sinais algébricos para os diferentes experimentos do planejamento $2^{3}$

\begin{tabular}{lccccccccc}
\hline \multicolumn{1}{c}{ Variável } & M1 & M2 & M3 & M4 & M5 & M6 & M7 & M8 \\
\hline $\mathrm{X}_{1}$ (PEG) & - & + & - & + & - & + & - & + \\
$\mathrm{X}_{2}$ (Ácido esteárico) & - & - & + & + & - & - & + & + \\
$\mathrm{X}_{3}$ (Óleo de mamona) & - & - & - & - & + & + & + & + \\
\hline
\end{tabular}

\section{Planejamento de experimentos $\left(2^{3}\right)$}

A formulação apresentada na Tabela 2 foi usada com poli(etileno-glicol) $\left(\mathrm{X}_{1}\right)$, ácido esteárico $\left(\mathrm{X}_{2}\right)$ e óleo de mamona $\left(\mathrm{X}_{3}\right)$ em dois níveis conforme a Tabela 4. Oito combinações foram conduzidas (Tabela 5) e três observações foram tomadas de cada combinação em particular para a estimativa da resistência à tração.

\section{Resultados e Discussão}

A Tabela 6 resume as propriedades reométricas como tempo de pré-cura $\left(\mathrm{t}_{\mathrm{s} 2}\right)$, tempo ótimo de cura $\left(\mathrm{t}_{90}\right)$ e torques mínimo $\left(\mathrm{M}_{1}\right)$ e máximo $\left(\mathrm{M}_{\mathrm{h}}\right)$, das diferentes composições de $\mathrm{NR}$ contendo sílica.

O tempo de pré-cura $\left(t_{\mathrm{s} 2}\right)$ refere-se a vulcanização prematura, isto é, a reticulação da composição durante o estágio de processamento. Isto reduz as propriedades plásticas da composição interferindo na operação de moldagem do produto final. O tempo de pré-cura, então, geralmente define o tempo dis- ponível para o processamento antes do início da vulcanização, em uma temperatura particular. O tempo ótimo de cura $\left(\mathrm{t}_{90}\right)$ é o tempo necessário durante a vulcanização para que uma dada quantidade de ligações cruzadas seja formada, conduzindo a um nível desejado de propriedades. O torque mínimo $\left(\mathrm{M}_{1}\right)$ está relacionado com a viscosidade ou plasticidade da composição não vulcanizada enquanto o torque máximo $\left(\mathrm{M}_{\mathrm{h}}\right)$ proporciona uma idéia da densidade de ligações cruzadas ou, indiretamente, se o estado de cura está sendo reduzido substancialmente ou não pela presença da sílica ${ }^{[6-9]}$.

A partir da Tabela 6, pode ser verificado que os experimentos M1, M3, M4, M6 e M7 não apresentam significativas diferenças no torque mínimo $\left(\mathrm{M}_{1}\right)$, enquanto os experimentos M2 e M5 mostram elevados valores para $M_{1}$. A adição de sílica em borrachas tende a aumentar a viscosidade mais rapidamente do que outras cargas. Isso é especialmente verdadeiro no caso de sílicas com elevada área específica. Contudo, certos ativadores usados em composições de NR contendo sílica produzem uma redução de viscosidade considerável, comparada a quantidade adicionada. Por exemplo, dietileno-glicol (DEG) ou trietanolamina (TEA) em $2 \mathrm{phr}$ podem reduzir a viscosidade Mooney em 30\% ou mais ${ }^{[10]}$. Plastificantes de origem vegetal demonstram ser vantajosos quando usados em NR, mas o óleo de mamona parece não atuar dessa forma.

Choi e Park ${ }^{[11]}$ observaram que o torque mínimo $\left(\mathrm{M}_{1}\right)$ aumenta com o tamanho do ácido graxo, do ácido n-cáprico $\left[\mathrm{CH}_{3}-\left(\mathrm{CH}_{2}\right)_{8}-\mathrm{CO}_{2} \mathrm{H}\right]$ para o ácido esteárico $\left[\mathrm{CH}_{3}-\left(\mathrm{CH}_{2}\right)_{16}-\mathrm{CO}_{2} \mathrm{H}\right]$. O incremento foi cerca de $0,012 \mathrm{~N} . \mathrm{m}$ por grupamento metileno. Por outro lado, o torque máximo e $\Delta$ torque $\left(\Delta \mathrm{M}=\mathrm{M}_{\mathrm{h}}-\mathrm{M}_{\mathrm{l}}\right)$ diminuem com o aumento do tamanho do ácido graxo. Isto foi explicado pelo número absoluto de moléculas de ácido graxo presentes na composição. Desde que o conteúdo total de ácido graxo foi constante, a razão molar relativa de ácido graxo diminui com o aumento do peso molecular. Além disso, foi suposto que parte do ácido graxo presente na composição move-se em direção a superfície da sílica para formar ligações por

Tabela 6. Tempo de pré-cura $\left(\mathrm{t}_{\mathrm{s} 2}\right)$, tempo ótimo de cura $\left(\mathrm{t}_{90}\right)$ e torques mínimo $\left(\mathrm{M}_{1}\right)$ e máximo $\left(\mathrm{M}_{\mathrm{h}}\right)$ para as diferentes composições de NR contendo sílica vulcanizadas em $150^{\circ} \mathrm{C}$

\begin{tabular}{ccccc}
\hline Experimento & $\begin{array}{c}\text { Tempo de pré-cura } \\
\left(\mathbf{t}_{\mathbf{s} 2}\right)(\mathbf{m i n})\end{array}$ & $\begin{array}{c}\text { Tempo ótimo de cura } \\
\left(\mathbf{t}_{\mathbf{9}}\right)(\mathbf{m i n})\end{array}$ & $\begin{array}{c}\text { Torque mínimo } \\
\left(\mathbf{l b}_{\mathbf{r}} \mathbf{i}\right)\end{array}$ & $\begin{array}{c}\text { Torque máximo } \\
\left(\mathbf{l b}_{\mathbf{r}} \mathbf{i}\right)\end{array}$ \\
\hline M1 & 5,7 & 40,5 & 9,3 & 41,0 \\
M2 & 5,6 & 13,8 & 11,4 & 61,2 \\
M3 & 12,0 & 33,6 & 9,1 & 41,8 \\
M4 & 7,1 & 15,6 & 9,2 & 67,6 \\
M5 & 11,4 & 45,3 & 15,5 & 43,8 \\
M6 & 5,2 & 12,3 & 8,8 & 60,0 \\
M7 & 9,0 & 21,3 & 8,9 & 48,4 \\
M8 & 4,2 & 11,8 & 6,7 & 56,0 \\
\hline
\end{tabular}


Tabela 7. Análise de variância para a resistência à tração

\begin{tabular}{lccccc}
\hline \multicolumn{1}{c}{ Variável } & $\begin{array}{c}\text { Soma dos } \\
\text { quadrados }\end{array}$ & $\begin{array}{c}\text { Graus de } \\
\text { liberdade }\end{array}$ & $\begin{array}{c}\text { Média } \\
\text { quadrada }\end{array}$ & Razão F & Valor de p \\
\hline PEG $\left(\mathrm{X}_{1}\right)$ & 230,588 & 1 & 230,588 & 80,02 & 0,0123 \\
Ácido esteárico $\left(\mathrm{X}_{2}\right)$ & 3,36701 & 1 & 3,36701 & 1,17 & 0,3927 \\
Óleo de mamona $\left(\mathrm{X}_{3}\right)$ & 10,2378 & 1 & 10,2378 & 3,55 & 0,2001 \\
$\mathrm{X}_{1} \mathrm{X}_{2}$ & 4,48501 & 1 & 4,48501 & 1,56 & 0,3385 \\
$\mathrm{X}_{1} \mathrm{X}_{3}$ & 26,8278 & 1 & 26,8278 & 9,31 & 0,0927 \\
Erro total & 5,76312 & 2 & 2,88156 & & \\
Total (corr.) & 281,269 & 7 & & & \\
\hline
\end{tabular}

hidrogênio com os silanóis ou, então, reagir com os silanóis formando ligações químicas. As moléculas de ácido graxo sobre a superfície da sílica podem evitar a adsorção de curativos e, então, resultar em um aumento do $\Delta \mathrm{M}$. Com mais moléculas de ácido graxo presentes no sistema, torna-se elevada a probabilidade de haver mais dessas moléculas sobre a superfície da sílica.

Para o máximo torque $\left(\mathrm{M}_{\mathrm{h}}\right)$, pode ser observado que melhores resultados são alcançados somente quando PEG está presente sozinho ou combinado com ácido esteárico e/ou óleo de mamona (M2, M4, M6 e M8). Com relação ao tempo ótimo de cura $\left(\mathrm{t}_{90}\right)$, obtém-se valores razoáveis somente quando PEG está presente.

Diversos caminhos têm sido sugeridos para modificar o sistema de vulcanização com enxofre de borrachas contendo a sílica como carga de reforço. A fim de melhorar o desempenho dos vulcanizados, é sugerido que: (i) combinações de dois ou mais aceleradores sejam usadas, onde pelo menos um deles seja da família dos tiazóis ou das sulfenamidas e ou outro podendo ser uma guanidina, tiuram ou ditiocarbamato; (ii) para teores de sílica acima de 20 phr, glicóis ou aminas sejam utilizadas. Desde que, $\mathrm{PEG}, \mathrm{HO}-\left(\mathrm{CH}_{2} \mathrm{CH}_{2} \mathrm{O}\right)_{n}-\mathrm{H}$, apresenta várias ligações do tipo éter capazes de formar ligações por hidrogênio com os grupos silanóis da superfície das partículas de sílica, isto o tornaria capaz de formar uma barreira entre tais partículas evitando as interações carga-carga e prevenindo a adsorção dos agentes de cura, conseqüentemente permitindo uma vulcanização mais eficiente (maior número de ligações cruzadas $)^{[10-12]}$.

Experimentos onde o ácido esteárico está presente sozinho (M3) ou combinado com o óleo de mamona (M7) não apresentam desempenho satisfatório quanto a vulcanização. O ácido esteárico funde abaixo da temperatura de vulcanização e durante o estágio de mistura reage facilmente com o $\mathrm{ZnO}$. Como $\mathrm{ZnO}$ está normalmente presente em excesso, não existirá nenhum ácido livre no sistema, somente $\mathrm{ZnO}$ e estearato de zinco. A formação de estearato de zinco "in situ" é uma importante característica desde que a adição do composto já preparado diminui a extensão da reticulação em sistemas 2,2'-dissulfeto de 2-bis-benzotiazol (MBTS) / enxofre ${ }^{[13]}$.
Fetterman ${ }^{[14]}$ estudando a influência que a sílica exerce sobre a vulcanização de borrachas concluiu que o "efeito de atraso" (vulcanização com maior $\mathrm{t}_{90}$ e menor densidade de ligações cruzadas) é diretamente proporcional a área específica, a quantidade e ao tamanho de partícula da sílica presente no sistema. Mukhopadhyay e $\mathrm{De}^{[15]}$ sugerem que a explicação mais plausível para a ação da sílica seria a ocorrência de uma reação de troca de íons entre os silanóis presentes na superfície da sílica e o estearato de zinco. Nesta reação, ácido esteárico é liberado para o sistema (Figura 1). McGill e Shelver ${ }^{[16]}$ mostraram que ácido esteárico e ácido benzóico reagem com MBTS e seus polisulfetos (MBTP) nas temperaturas de vulcanização para formar complexos ácido-acelerador. A destruição dos polisulfetos pelos ácidos carboxílicos reduz a concentração de MBTP disponível e traz um impacto negativo sobre a vulcanização. Uma discussão mais abrangente sobre a rota química e a importância dos polisulfetos no curso da da vulcanização pode ser encontrada em artigo anterior ${ }^{[17]}$.

O desempenho do óleo de mamona sozinho (M5) em termos de propriedades reométricas não é significativo para as composições de NR-sílica, como mostra a Tabela 6. Ismail et $a l .^{[1-5]}$ observaram que os ácidos graxos presentes no óleo de palma atuam de modo similar ao ácido benzóico, ou seja, atrasam o início da vulcanização. Foi verificado que o tempo de pré-cura $\left(\mathrm{t}_{\mathrm{s} 2}\right)$ e o tempo ótimo de cura $\left(\mathrm{t}_{90}\right)$ aumentam com

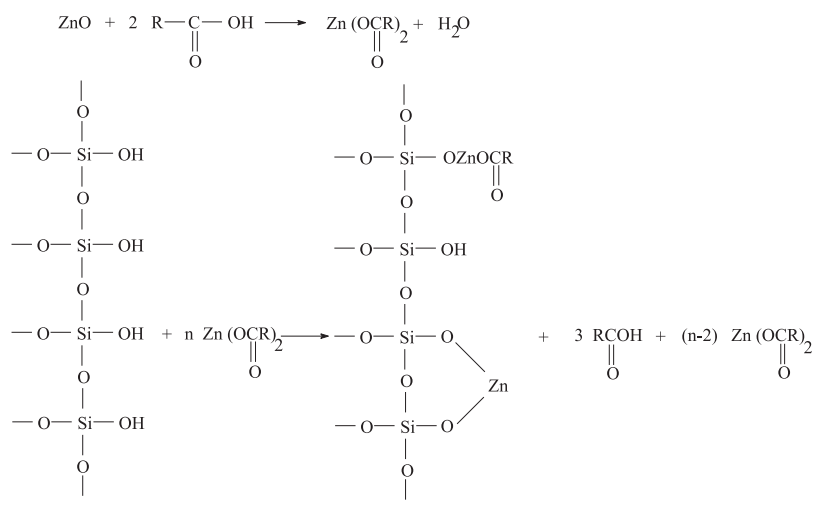

Figura 1. Reação entre os grupamentos silanóis, presentes na carga de sílica, e o estearato de zinco ${ }^{[15]}$ 


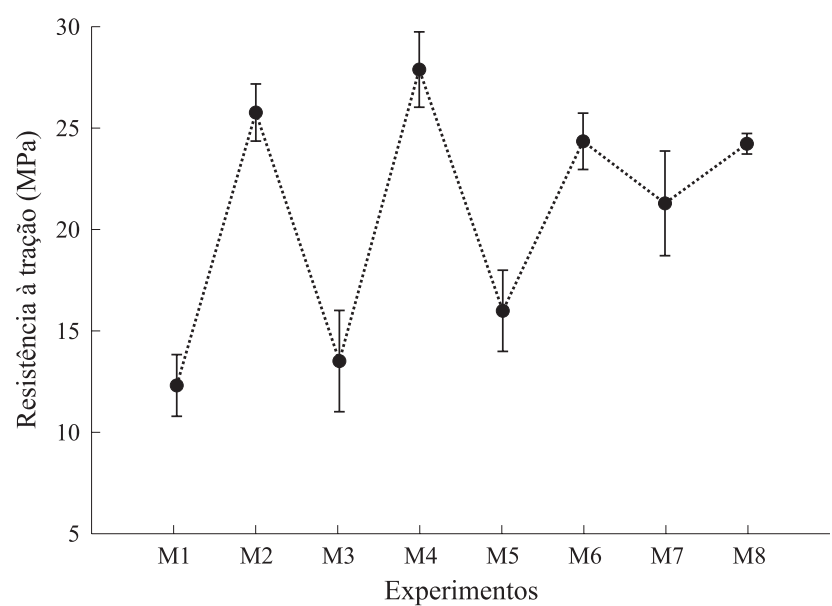

Figura 2. Resistência à tração das composições de NR-sílica vulcanizadas em $150{ }^{\circ} \mathrm{C}$

o aumento da concentração de óleo de palma em composições de NR e ENR.

Através da análise de variância para o planejamento $2^{3}$, os efeitos médios e as variáveis mais significativas para a vulcanização das composições de NR contendo sílica foram estimados, usando-se a resistência à tração (Fig.2) como variável de controle. Montgomery ${ }^{[18]}$ cita a metodologia de cálculo e a Tabela 7 resume os efeitos das variáveis $\mathrm{X}_{1}, \mathrm{X}_{2}$ e $\mathrm{X}_{3}$ sobre a resistência à tração. A partir da Tabela 7 , pode ser observado que o poli(etileno-glicol) $\left(\mathrm{X}_{1}\right)$ é a única variável significativa para o processo de cura. Sozinho ou combinado, PEG produz um efeito positivo considerável sobre a vulcanização conduzindo a um melhor desempenho mecânico. A Eq.1 pode ser usada para correlacionar os resultados de tração com as variáveis investigadas:

$$
\begin{aligned}
\mathrm{T}= & \text { média }+\mathrm{A}^{*} \mathrm{X}_{1}+\mathrm{B}^{*} \mathrm{X}_{2}+\mathrm{C}^{*} \mathrm{X}_{3}+\mathrm{AB}^{*} \mathrm{X}_{1} \mathrm{X}_{2}+ \\
& \mathrm{AC} * \mathrm{X}_{1} \mathrm{X}_{3}+\mathrm{BC}^{*} \mathrm{X}_{2} \mathrm{X}_{3}+\mathrm{ABC} * \mathrm{X}_{1} \mathrm{X}_{2} \mathrm{X}_{3}
\end{aligned}
$$

Onde:

$\mathrm{T}=$ variável de controle (resistência à tração);

$\mathrm{X}_{1}, \mathrm{X}_{2}, \mathrm{X}_{3}=$ variáveis do processo;

$\mathrm{A}, \mathrm{B}, \mathrm{C}=$ constantes que estão relacionadas a influência das variáveis;

$\mathrm{AB}, \mathrm{AC}, \mathrm{BC}, \mathrm{ABC}=$ constantes que estão relacionadas com as interações entre as variáveis;

Após a análise da variância para o planejamento $2^{3}$, a equação final (Eq.2) para o estudo das composições de NRsílica com concentrações de PEG $\left(\mathrm{X}_{1}\right)$, ácido esteárico $\left(\mathrm{X}_{2}\right)$ e óleo de mamona $\left(\mathrm{X}_{3}\right)$ usadas como variáveis de processo e a resistência à tração como variável de controle, será:

$$
\begin{aligned}
\mathrm{T}= & 10,2575+7,94875 * \mathrm{X}_{1}+1,118 \mathrm{X}_{2}+1,185 \mathrm{X}_{3}- \\
& 0,599 * \mathrm{X}_{1} \mathrm{X}_{2}-0,7325 * \mathrm{X}_{1} \mathrm{X}_{3}
\end{aligned}
$$

\section{Conclusões}

O potencial do óleo de mamona como um ativador foi investigado no processo de vulcanização de composições de borracha natural (NR) contendo sílica. Após o planejamento de experimentos foi observado, através dos resultados obtidos, que o óleo de mamona sozinho (experimento M5) não apresenta significativa melhora das características de vulcanização.

Quando o óleo de mamona é combinado com ácido esteárico (M7) um melhor desempenho é alcançado diferentemente dos experimentos onde estes ingredientes estão presentes sozinhos (M5 e M3, respectivamente). No entanto, esse efeito sinérgico ainda é pequeno para evitar a adsorção dos ingredientes responsáveis pela cura pela superfície da sílica e/ou as fortes interações carga-carga.

\section{Agradecimentos}

Os autores agradecem à CAPES pelo suporte financeiro.

\section{Referências Bibliográficas}

1. Ismail, H; Ruhaizat, T. A. - Polym.-Plast. Technol. Eng., 37, p.483, (1998).

2. Ismail, H.; Ng, C. T.; Ishiaku, U. S.; Ishak, Z. A. M. Polym.-Plast. Technol. Eng., 38, p.127, (1999).

3. Ismail, H. - Polym.-Plast. Technol. Eng., 38, p.805, (1999).

4. Ismail, H.; Salmiah, I. - Intern. J. Polymeric Mater., 43, p.115, (1999).

5. Ismail, H.; Kamal, S. K.; Mark, S. E. - Intern. J. Polymeric Mater., 49, p.191, (2001).

6. Coran, A. Y. - "Science and Technology of Rubber" - cap.7, F. R. Eirich (ed.), Academic Press Inc., London, (1978).

7. Boonstra, B. B. - "Rubber Technology and Manufacture" - cap.7, C. M. Blow (ed.), Newnes-Butterworth, London, (1971).

8. Morrinson, N. J.; Porter, M. - Rubber Chem. Technol., 37, p.650, (1964).

9. Chough, S. H.; Chang, D. H. - J. Appl. Polym. Sci., 61, p.449, (1996).

10. Wagner, M. P. - Rubber Chem. Technol., 49, p.703, (1976).

11. Choi, S. S.; Park, S. - Korea Polym. J., 9, p.92, (2001).

12. Loo, C. T. - Polymer, 15, p.357, (1974).

13. Campbell, R. H.; Wise, R. W. - Rubber Chem. Technol., 37, p.635, (1964).

14. Fetterman, M. Q. - Rubber Chem. Technol., 46, p.927, (1973).

15. Mukhopadhyay, R.; De, S. K. - Rubber Chem. Technol., 52, p.263 (1979).

16. McGill, W. J.; Shelver, S. R. - J. Appl. Polym. Sci., 72, p.999, (1999).

17. Costa, H. M.; Visconte, L. L. Y.; Nunes, R. C. R.; Furtado, C. R. G. - Polímeros: Ciência e Tecnologia, 13(2), p.125, (2003).

18. Montgomery, D. C. - "Design and Analysis of Experiments", John-Wiley, New York, (1984).

Recebido: 23/10/03

Aprovado: 19/12/03 